\title{
Estimation of carcinoembryonic antigen in ulcerative colitis with special reference to malignant change
}

\author{
J. B. DILAWARI ${ }^{1}$, J. E. LENNARD-JONES, A. M. MACKAY, \\ JEAN K. RITCHIE, AND H. G. STURZAKER \\ From St Mark's and the Central Middlesex Hospitals and the Chester Beatty Research Institute, London
}

SUMMARY The levels of plasma carcinoembryonic antigen (CEA) were estimated in 59 control subjects attending St Mark's Hospital and in 139 patients with uncomplicated ulcerative colitis. There was little difference in the CEA levels in the two groups. In the colitic patients, the actual CEA values could not be correlated with the age of the patient, the activity of the disease, the extent of bowel involvement, or the length of history.

In addition, seven colitic patients with severe dysplastic changes in the rectal mucosa and seven patients with established carcinoma in colitis were studied. With one exception in each group, the CEA levels in these patients were within the range shown by the St Mark's Hospital control population.

Patients with ulcerative colitis have an increased risk of developing carcinoma of the large bowel so any test which would help in the early detection of malignant change or, better, predict the likelihood of a cancer developing, would be welcome. Following the initial work of Gold and Freedman (1965) and Krupey, Gold, and Freedman (1967), it was thought that the estimation of carcinoembryonic antigen (CEA) was a specific test for detecting carcinoma of the colon and rectum (Thomson, Krupey, Freedman, and Gold, 1969), but subsequent work has demonstrated elevated CEA levels in patients with carcinoma in many other sites (Laurence, Stevens, Bettelheim, Darcy, Leese, Turberville, Alexander, Johns, and Neville, 1972), in heavy smokers (Stevens and Mackay, 1973), in patients with chronic bronchitis (Laurence et al, 1972), with pancreatitis (Khoo and Mackay, 1973), and in adults with seropositive rheumatoid arthritis (Unger, Panayi, and Lessof, 1974). Before this study was begun it had already been shown that CEA levels were also raised in patients with ulcerative colitis (Lo Gerfo, Krupey, and Hansen, 1971; Wight and Gazet, 1972). Nevertheless, in 1972, it was decided to investigate CEA levels in patients with colitis attending St Mark's and the Central Middlesex Hospitals and to ${ }^{1}$ Please address requests for reprints to J.B.D. at The Middlesex Hospital, London W1

Received for publication 23 January 1975. correlate the findings with various clinical aspects of the disease. In particular, we wished to see whether or not CEA levels could be correlated with the presence of carcinoma or of dysplastic epithelial changes without carcinoma (Morson and Pang, 1967).

\section{Technical Details}

Ten $\mathrm{ml}$ of blood obtained by venepuncture was collected into bottles containing edetic acid. After centrifuging, the plasma was stored at $-20^{\circ} \mathrm{C}$ within three hours of collection until transferred to the Chester Beatty Institute for storage at $-70^{\circ} \mathrm{C}$.

Carcinoembryonic antigen was estimated at this Institute by a modification of the double-antibody technique described by Egan, Lautenschleger, Coligan, and Todd (1972). Clinical details were not available to the technicians performing the CEA estimations and the results were not correlated with the clinical state of the patients until the end of the study.

\section{Groups of Patients Studied}

1 CHESTER BEATTY STAFF

Seventy apparently healthy, mainly young, medical and technical staff from the Chester Beatty Institute were used as one control group. 


\section{HOSPITAL CONTROL GROUP}

This group consisted of 59 patients attending St Mark's Hospital in whom there was no evidence of colitis or malignant tumour. The final diagnoses in these patients are shown in table I. In each patient, blood for CEA estimation was obtained before definitive treatment was undertaken.

\begin{tabular}{lc}
\hline Diagnosis & Number of Patients \\
\hline Idiopathic megacolon or Hirschsprung's disease & 7 \\
Diverticular disease (without inflammation) & 5 \\
Rectal prolapse & 5 \\
Haemorrhoids & 18 \\
Anal fissure & 6 \\
Perianal haematoma & 3 \\
Other anal conditions & 4 \\
Miscellaneous conditions & 11 \\
\hline
\end{tabular}

Table I Diagnosis in 59 patients considered as hospital control group

\section{PATIENTS WITH UNCOMPLICATED \\ ULCERATIVE COLITIS}

One hundred and thirty-nine patients without evidence of dysplastic change in the rectal mucosa or carcinoma were investigated. The diagnosis was made on the usual clinical criteria supported by radiological and histological evidence.

\section{PATIENTS WITH ULCERATIVE COLITIS AND EPITHELIAL DYSPLASIA}

There were seven patients in this group in whom the dysplastic changes found in the rectal mucosal biopsy were severe enough to fulfil the criteria described by Morson and Pang (1967). Two of the seven patients had extensive disease as defined below (length of history nine and 10 years respectively), two showed distal involvement only (length of history 19 and 40 years respectively), and three patients had been treated previously by colectomy and ileorectal anastomosis (total length of history more than 10 years in each case).

\section{PATIENTS WITH ESTABLISHED CARCINOMA IN ULCERATIVE COLITIS}

The clinical details of the seven patients in this group are shown in table II.

\section{Clinical Parameters}

Four clinical parameters were studied. These were age, activity of the disease, length of history, and the extent of colonic involvement.

\section{DISEASE ACTIVITY}

For simplicity, the disease was described as active or inactive; the condition was considered to be inactive if the patient had no symptoms and sigmoidoscopy showed an inactive mucosa.

\section{LENGTH OF HISTORY}

This was classified into $(a)$ patients with a history of less than one year; $(b)$ with a history of one to nine years inclusive; and $(c)$ symptoms for 10 years or more.

\section{EXTENT OF INVOLVEMENT}

This was assessed radiologically and was categorized as follows: (a) distal (disease extending no further than the iliac crest); (b) left-sided (no further than the splenic flexure); (c) substantial (no further than the hepatic flexure); (d) extensive (involving the hepatic flexure or more proximal colon).

\section{Results}

The overall results are shown in figure 1 . All the 70 healthy control subjects from the Chester Beatty Institute had CEA levels of less than $17.5 \mathrm{ng} / \mathrm{ml}$. These results are different from the figures found in the controls drawn from the St Mark's Hospital population, eight of whom had values higher than $17.5 \mathrm{ng} / \mathrm{ml}$ with a range from 1 to $36 \mathrm{ng} / \mathrm{ml}$.

In general, there is little difference in the results for patients with colitis and the St Mark's Hospital population. In the colitic patients, no correlation

\begin{tabular}{|c|c|c|c|c|c|c|}
\hline Case No. & $\operatorname{sex}$ & $\begin{array}{l}\text { Age } \\
(y r)\end{array}$ & $\begin{array}{l}\text { Length of History } \\
\text { (years) }\end{array}$ & Site of Tumour & $\begin{array}{l}\text { Dukes' } \\
\text { Classification }\end{array}$ & $\begin{array}{l}\text { Preoperative CEA } \\
\text { Level }(n g / m l)\end{array}$ \\
\hline $\begin{array}{l}1 \\
2 \\
3^{1} \\
4^{2} \\
5 \\
6 \\
7\end{array}$ & $\begin{array}{l}\mathbf{M} \\
\mathbf{F} \\
\mathbf{M} \\
\mathbf{M} \\
\mathbf{M} \\
\mathbf{M} \\
\mathbf{M}\end{array}$ & $\begin{array}{l}53 \\
53 \\
61 \\
32 \\
32 \\
24 \\
63\end{array}$ & $\begin{array}{l}25 \\
26 \\
13 \\
14 \\
10 \\
12 \\
23\end{array}$ & $\begin{array}{l}\text { Caecum } \\
\text { Rectum } \\
\text { Rectum } \\
\text { Rectum } \\
\text { Sigmoid } \\
\text { Rectum } \\
\text { Rectum }\end{array}$ & $\begin{array}{l}\text { A } \\
\text { A } \\
\dot{A} \\
\text { Unknown } \\
\text { C1 } \\
\text { A } \\
\text { B }\end{array}$ & $\begin{array}{r}21 \cdot 5 \\
105.0 \\
16.0 \\
10.9 \\
15.2 \\
9.0 \\
12.0\end{array}$ \\
\hline
\end{tabular}

Table II Clinical details of seven patients with carcinoma complicating colitis

${ }^{1}$ Emergency limited resection four years previously elsewhere for carcinoma of the caecum presenting as appendicitis.

Anterior resection (peritoneal deposits) four months previously elsewhere. Recurrent rectal carcinoma at time of CEA estimation. 


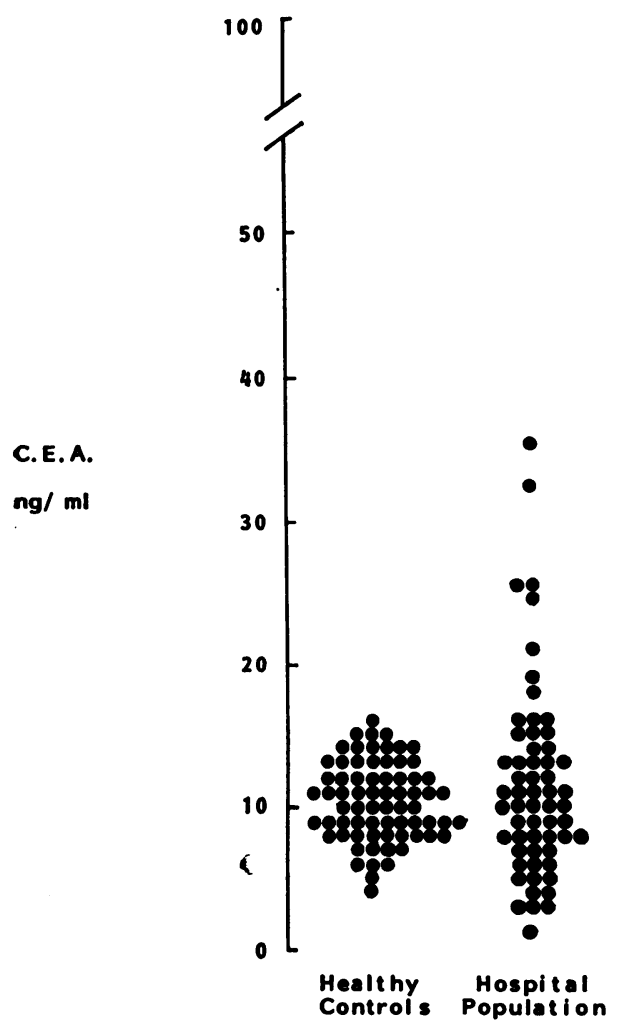

$\bullet 105$

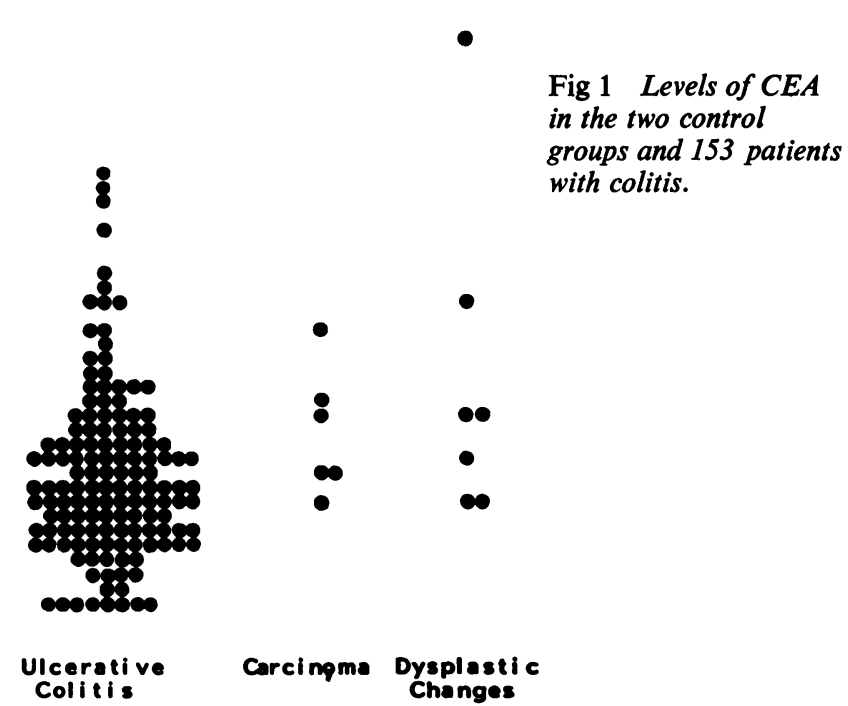

Fig 1 Levels of CEA in the two control groups and 153 patients with colitis.

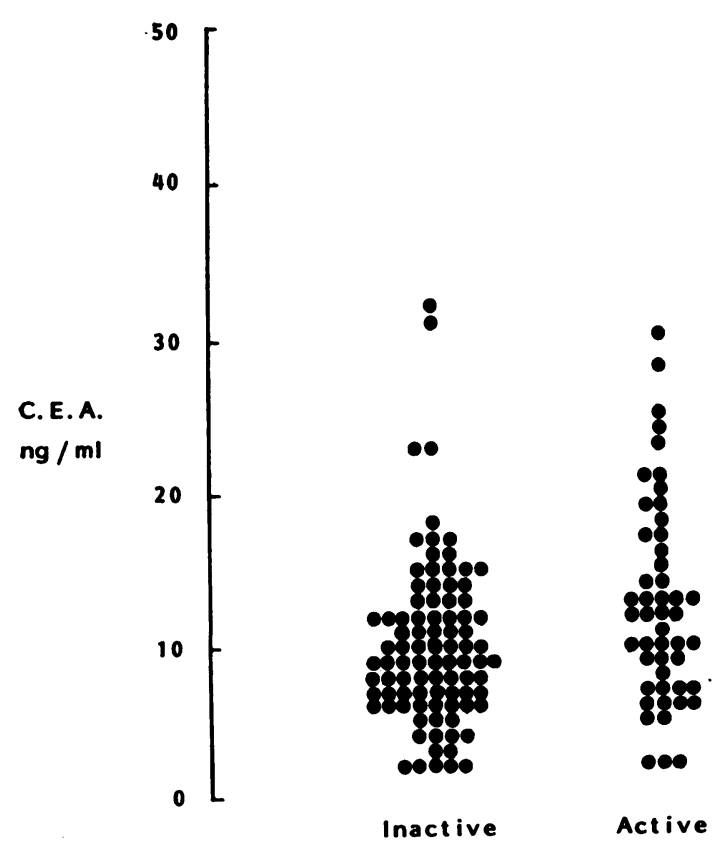

Fig 2 Levels of CEA and activity of the disease. could be established between the age of the patient and the actual CEA levels.

Similarly, no relationship could be found between the activity of the disease and the CEA levels (fig 2); serial estimations in a number of patients also failed to show any such correlation. Furthermore, the CEA values were of similar range when the patients were subdivided according to the extent of bowel involvement (fig 3).

All patients with a history of less than one year showed CEA levels below $20 \mathrm{ng} / \mathrm{ml}$ (fig 4), and there was no difference in the values for patients with a history of 10 years or more compared with those who had had symptoms for between one and nine years. In particular, in the group with a history of 10 years or over and extensive disease, the CEA levels were indistinguishable from those in other categories.

Only one patient among the seven with dysplastic changes in the rectal mucosa had a CEA level above the values found in the hospital control group (fig 1). This patient, a woman of 49 years, with a 10-year history and extensive colonic involvement, showed a CEA value of $41 \mathrm{ng} / \mathrm{ml}$. In the other six patients, the CEA levels were well within the hospital control range.

One patient (table II, case 2) among the seven with 


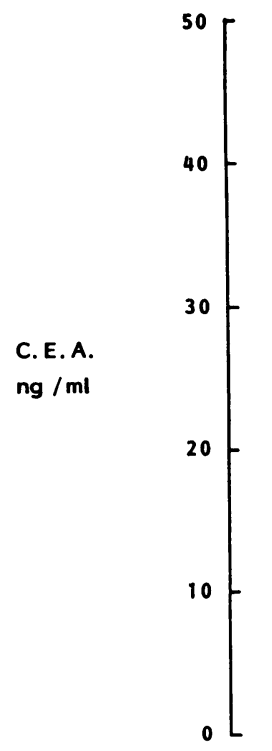

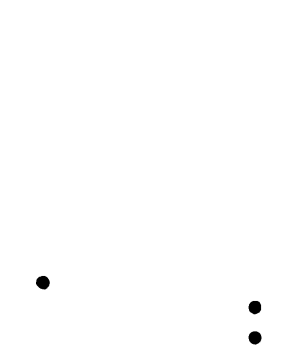

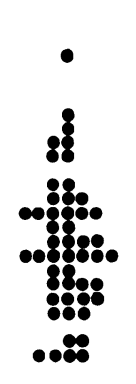

Distal

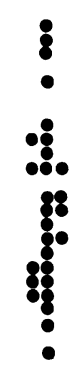

Left Sided

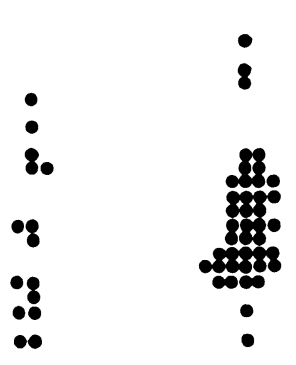

Substantial
Fig 3 Values for CEA and extent of bowel involvement. malignant change showed a CEA level of $105 \mathrm{ng} / \mathrm{ml}$. The other six patients, including case 4 with recurrent growth and peritoneal metastases, all had CEA values within the range shown by the St Mark's control group.

\section{Discussion}

One of the features of this study was the extent to which the CEA values in the St Mark's Hospital control group differed from those in the Chester Beatty control subjects. The latter were all healthy staff whereas the St Mark's group were patients showing some pathological condition. Among this group, however, there was no one particular condition associated with a CEA level higher than that shown by the healthy control group. In neither group was allowance made for smoking habits. The

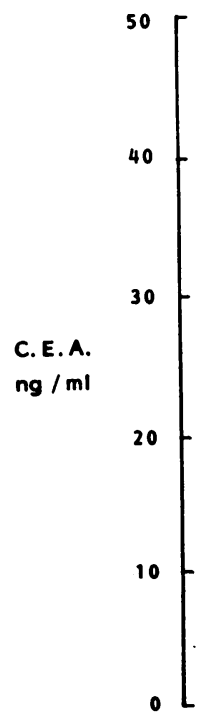

$\Delta$ Extensive Colitis

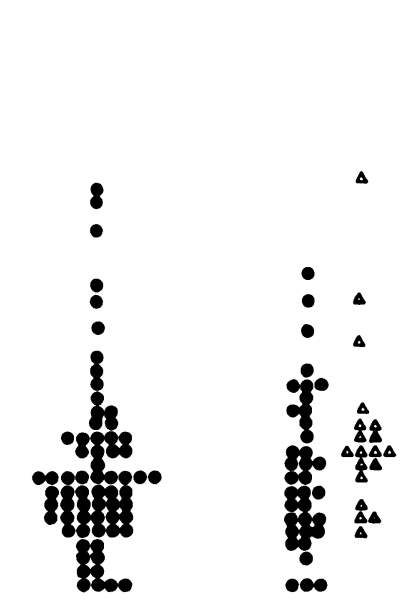

Fig 4 Values for CEA and the duration of the disease. 
difference in the values between the two control groups might be explained by the suggestion that CEA levels may be raised in other conditions so far uninvestigated. This study emphasizes the importance of using, as controls, subjects from a population similar to that under investigation.

Previous work in patients with ulcerative colitis has suggested that CEA levels may be related to the age of the patient (Rule, Goleski-Reilly, Sachar, Vandevoorde, and Janowitz, 1973), the length of history and the extent of the disease (Rule et al, 1972), and to the activity of the disease (Rule et al, 1972; Moore, Kantrowitz, and Zamcheck, 1972; Khoo, Hunt, and Mackay, 1973). In contradistinction to these authors, the present study of a considerably larger series of patients showed no relationship to any of these features. This corroborates the findings in two other British series. Wight and Gazet (1972), and Booth, King, Leonard, and Dykes (1973) investigated 30 and 61 colitic patients respectively and were unable to demonstrate any correlation between CEA levels and the clinical features already mentioned.

Table III summarizes the reported series of CEA estimations in ulcerative colitis in which patients with either epithelial dysplasia or carcinoma were included.

\begin{tabular}{lcll}
\hline Authors & $\begin{array}{l}\text { Total No. } \\
\text { of Patients }\end{array}$ & $\begin{array}{l}\text { No. with } \\
\text { Dysplasia }\end{array}$ & $\begin{array}{l}\text { No. with } \\
\text { Carcinoma }\end{array}$ \\
\hline Wight and Gazet (1972) & 30 & $2(0)^{1}$ & 0 \\
Moore et al (1972) & 46 & 0 & $1(1)$ \\
Khoo et al (1973) & 77 & 0 & $2(2)$ \\
Booth et al (1973) & 61 & $3(1)$ & $1(0)$ \\
Present series & 153 & $7(1)$ & $7(1)$
\end{tabular}

Table III Carcinoembryonic antigen in ulcerative colitis: series containing patients with dysplasia or carcinoma

${ }^{1}$ Figures in parentheses denote patients with raised CEA levels.

The actual CEA levels have not been given in table III because the methods of assay have varied. Four out of the five patients with dysplasia previously reported showed CEA levels within the normal range for the method used. Our experience is similar in that only one of our seven patients with this change had a level greater than that shown by the St Mark's Hospital control population.

Among the four patients with carcinoma in colitis already reported, a normal CEA value was found in the patient described by Booth et al (1973), using a technique similar to that of the present study. Moore et al (1972), using a less sensitive technique, found a persistently positive serum assay in their only patient with coexistent carcinoma. Khoo et al (1973) found that CEA was not detectable in serum from colitic patients after extraction with perchloric acid unless the patient had a coexistent carcinoma. This occurred in their two patients with carcinoma and, as a result, they stated that CEA assay was a useful means of detecting carcinomatous change in ulcerative colitis. Owing to technical differences in the method of assay, it has not proved possible to substantiate or refute the findings of Khoo et al (1973) for the seven patients with carcinoma and colitis in this series.

In the present study, only one of the seven patients with established carcinoma in ulcerative colitis had a CEA level $(105 \mathrm{ng} / \mathrm{ml})$ outside the control range (table II case 2). It is interesting that the CEA level in this patient fell to $52.5 \mathrm{ng} / \mathrm{ml}$ one week after total proctocolectomy, to $30.8 \mathrm{ng} / \mathrm{ml}$ two weeks postoperatively, and to $18.0 \mathrm{ng} / \mathrm{ml}$ three months later.

These disappointing findings of a raised CEA level in only one patient in each group of those with dysplasia or carcinoma show that little help is to be expected in the early detection of malignant change in patients especially at risk, and that with established carcinoma this test is no more helpful than conventional investigations. However, it may be worthwhile to perform serial CEA estimations in any patient where the preoperative level is raised in the presence of carcinoma in colitis to act as a monitor of the completeness of excision.

In this study CEA values in ulcerative colitis have shown no correlation with the length of history, the extent of the disease, or the degree of activity. It seems unlikely that malignant change would be detected by this test earlier than by other methods of investigation and we see no value in routine CEA estimations in patients with ulcerative colitis.

J.B.D. was supported by a grant from the Medical Research Council and H.G.S. was supported by the St Mark's Research Foundation.

References

Booth, S. N., King, J. P. G., Leonard, J. C., and Dykes, P. W. (1973). Serum carcinoembryonic antigen in clinical disorders. Gut, 14, 794-799.

Egan, M. L., Lautenschleger, J. T., Coligan, J. E., and Todd, C. W. (1972). Radioimmune assay of carcinoembryonic antigen. Immunochemistry, 9, 289-299.

Gold, P., and Freedman, S. O. (1965). Demonstration of tumorspecific antigens in human colonic carcinomata by immunological tolerance and absorption techniques. J. exp. Med., 121, 439-462.

Khoo, S. K., Hunt, P. S., and Mackay, I. R. (1973). Studies of carcinoembryonic antigen activity of whole and extracted serum in ulcerative colitis. Gut, 14, 545-548.

Khoo, S. K., and Mackay, I. R. (1973). Carcinoembryonic antigen in serum in diseases of the liver and pancreas. J. clin. Path. 26, 470-475.

Krupey, J., Gold, P., and Freedman, S. O. (1967). Purification and characterization of carcino-embryonic antigens of the human digestive system. Nature (Lond.), 215, 67-68. 
Laurence, D. J. R., Stevens, U., Bettelheim, R., Darcy, D., Leese, C., Turberville, C., Alexander, P., Johns, E. W., and Neville, A. M. (1972). Role of plasma carcinoembryonic antigen in diagnosis of gastrointestinal, mammary, and bronchial carcinoma. Brit. med. J., 3, 605-609.

Lo Gerfo, P., Krupey, J., and Hansen, H. J. (1971). Demonstration of an antigen common to several varieties of neoplasia. New Engl. J. Med., 285, 138-141.

Moore, T. L., Kantrowitz, P. A., and Zamcheck, N. (1972). Carcinoembryonic antigen (CEA) in inflammatory bowel disease. $J$. Amer. med. Ass., 222, 944-947.

Morson, B. C., and Pang, L. S. C. (1967). Rectal biopsy as an aid to cancer control in ulcerative colitis. Gut, 8, 423-434.

Rule, A. H., Goleski-Reilly, C., Sachar, D. B., Vandevoorde, J., and Janowitz, H. D. (1973). Circulating carcinoembryonic antigen (CEA): Relationship to clinical status of patients with inflammatory bowel disease. Gut, 14, 880-884.

Stevens, D. P., and Mackay, I. R. (1973). Increased carcinoembryonic antigen in heavy cigarette smokers. Lancet, 2, 1238-1239.

Thomson, D. M. P. Krupey, J., Freedman, S. O., and Gold, P. (1969). The radioimmunoassay of circulating carcinoembryonic antigen of the human digestive system. Proc. nat. Acad. Sci. (Wash.), 64, 161-167.

Unger, A., Panayi, G. S., and Lessof, M. H. (1974). Carcinoembryonic antigen in rheumatoid arthritis. Lancet, 1, 781-783.

Wight, D. G. D., and Gazet, J.-C. (1972). Carcino-embryonic antigen levels in inflammatory disease of the large bowel. Proc. roy. Soc. Med., 65, 967-968. 